\title{
Comparison of estimates of travel time losses on high-capacity roads
}

\section{Journal Article}

Author(s):

Jäggi, Boris; Hohmann, Sandra; Axhausen, Kay W. (1); Geistefeldt, Justin

Publication date:

2014

Permanent link:

https://doi.org/10.3929/ethz-b-000069499

Rights / license:

In Copyright - Non-Commercial Use Permitted

Originally published in:

Transportation Research Record 2461, https://doi.org/10.3141/2461-03 


\title{
Comparison of Estimates of Travel Time Losses on High-Capacity Roads
}

\author{
Boris Jäggi, Sandra Hohmann, Kay W. Axhausen, and Justin Geistefeldt
}

\begin{abstract}
This paper compares two approaches to estimating travel time losses on freeways that are based on a whole-year analysis. Both approaches are intended to improve the design process for freeways by accounting for the annual traffic demand profile as well as short time variance of demand and capacity. One approach estimates breakdown probability and delayrelated time losses by using a probabilistic model. The other approach uses Monte Carlo simulation to estimate travel time losses at freeway bottlenecks on the basis of a queuing model with stochastic demand and capacity. Both approaches are based on annual hourly demand profiles. The approaches are compared for demand profiles and deliver similar but not equal results. Travel time losses for both approaches increase exponentially with traffic volume, with the simulation-based approach consistently generating higher time losses for higher traffic volumes. Both approaches are a substantial improvement on current design procedures, are easy to apply, and are recommended for adoption in traffic analysis guidelines.
\end{abstract}

In the highway analysis procedures given in guidelines such as the Highway Capacity Manual in the United States (1), the German highway capacity manual HBS (2), or the recently withdrawn Swiss code SN 640 016A, the expected traffic demand is compared with the capacity in a deterministic manner. The level of service (LOS) is calculated for one specific hour, and it is estimated whether the LOS for a given time frame in the future is acceptable. A more detailed consideration compares the expected economic benefit of travel time savings of the users with the investment and maintenance costs in the relevant cost-benefit guidelines (SN 641 820). The proposal for a new Swiss code (SN 640 016b) incorporates a different approach and moves away from the current design process that considers only one representative hour of the whole year (3). The proposal shows how these current design approaches reflect the technical possibilities of the period of their development and how they stand alone conceptually in contemporary transport and engineering codes. New design approaches typically try to incorporate the following elements to achieve a more realistic estimate of total costs of the design, which then can be used for comparison with possible alternatives:

1. Dynamics of traffic demand over the relevant time period (hour, day, year, several years);

2. Short-term variance of traffic demand, for example, within $1 \mathrm{~h}$;

B. Jäggi and K.W. Axhausen, Institute for Transport Planning and Systems, ETH Zurich, CH-8093 Zurich, Switzerland. S. Hohmann and J. Geistefeldt, Institute for Traffic Engineering and Management, Ruhr University Bochum, Universitaetsstr. 150, D-44801 Bochum, Germany. Corresponding author: B. Jäggi, boris.jaeggi@ ivt.baug.ethz.ch.

Transportation Research Record: Journal of the Transportation Research Board, No. 2461, Transportation Research Board of the National Academies, Washington, D.C., 2014, pp. 16-24.

DOI: $10.3141 / 2461-03$
3. Short-term and local variance of infrastructure capacity, for example, of a dam, a beam, or the combination of infrastructure and participant because of weather, material failure, constructional variance, concentration deficits, or driver distraction; and

4. Calculation of generalized user costs to various extents, for example, comprehensive costs such as in a cost-benefit analysis or only waiting time in the case of traffic signal systems.

Table 1 gives an overview of the current state of capacity design guidelines in Switzerland and the United States.

Another approach for traffic performance assessment is a Monte Carlo simulation as described by Brilon et al. (4). The assessment of traffic flow quality is based on a deterministic queuing model with stochastic demand and capacity values. The approach was used for several traffic engineering applications in Germany. The model was adapted by Mehran and Nakamura to evaluate congestion relief schemes on expressways in Japan (5).

Both approaches are based on the concept of stochastic capacities (6-8). The discussion seeks to develop new procedures that include all four elements, notably by developing stochastic simulations, despite its problems with computation time and user-friendliness.

The paper compares the behavior and the characteristics for various demand profiles and traffic loads of the two approaches. The approaches are the whole-year analysis-probabilistic delay model (WYA-PDM), developed by Bernard in his dissertation at the Institute for Transport Planning and Systems at the Swiss Federal Institute of Technology Zurich (9), and the whole-year analysisqueuing model (WYA-QM), developed by Zurlinden (10) and further enhanced by Brilon et al. (6) at the Institute for Transportation and Traffic Engineering at Ruhr University Bochum.

\section{OVERVIEW}

In the following two sections, the approaches are described in more detail. The two approaches are then compared by means of standardized annual demand profiles from the Swiss code SN 640 005b and according to Pinkofsky (11). These demand profiles are used in Swiss and German practice for several traffic engineering tasks, for example, estimating annual average daily traffic from short-term counts, to choose cross sections in the highway design process, or in simplified form for cost-benefit calculations. Travel time losses are calculated and compared for various levels of average annual daily traffic. Finally, conclusions are drawn.

\section{WYA-PDM APPROACH}

The WYA-PDM approach includes demand profiles over the course of 1 year, delays caused by the use of other road participants, breakdown probabilities, and early and late delays caused by the 
TABLE 1 Aspects Considered in Cross-Section Design Guidelines in Switzerland and the United States

\begin{tabular}{lllll}
\hline Guideline & $\begin{array}{l}\text { Long-Term } \\
\text { Dynamics }\end{array}$ & $\begin{array}{l}\text { Short-Term } \\
\text { Flow } \\
\text { Variance }\end{array}$ & $\begin{array}{l}\text { Short-Term } \\
\text { Capacity } \\
\text { Variance }\end{array}$ & $\begin{array}{l}\text { Generalized } \\
\text { Costs }\end{array}$ \\
\hline $\begin{array}{l}\text { Cross section } \\
\text { Signals }\end{array}$ & No & No & No & No \\
$\begin{array}{l}\text { Roundabouts } \\
\begin{array}{l}\text { Intersections } \\
\text { without } \\
\text { signals }\end{array}\end{array}$ & No & CH/USA & No & No \\
CBA & No & No & CH/USA & No \\
\hline
\end{tabular}

NotE: $\mathrm{CH}=$ Switzerland; $\mathrm{CBA}=$ cost-benefit analysis.

breakdown. The approach evaluates a highway section with a given load by summing generalized costs over all road users who should be considered in highway design. Other elements, not accounted for in this approach, are environmental costs, mode choice, and induced demand effects. For this, a cost-benefit analysis on a higher level is necessary.

This section summarizes the approach for high-capacity road design developed by Bernard (9) and Bernard and Axhausen (3). The parameters given here were estimated with a 5-year sample of 13 automatic motorway counting stations in Switzerland. The approach is based on variables that are explained in the following subsections. The basic idea is to estimate both the delays caused by traffic breakdowns and the resulting costs from schedule delays affecting travelers. Traffic breakdowns are random events caused by a violation of the instantaneous capacity constraint occurring when capacity and demand vary during short time intervals around their longer-term average.

The breakdowns generate an event of below target speed of a certain duration as a function of the current average flow. The approach therefore needs to estimate breakdown probability, breakdown duration, and the resulting additional user costs.

\section{Breakdown Probability}

The breakdown probability $\left(P_{b}\right)$ depends on the 60-min saturation rate $\left(r_{60}\right)$, that is, the ratio between demand and mean capacity of the cross section. The breakdown probability is calculated as the cumulative probability of a standard normal distribution with the shape

$P_{b}(\beta)=\frac{1}{\sqrt{2 \pi}} \int_{-\infty}^{-\beta} e^{\frac{-1}{2} x^{2}} d x$

where $\beta$ is the ratio of the mean divided by the standard deviation of the reserve capacity, or $\beta=\mu_{R} / \sigma_{R}$.

The mean $\left(\mu_{R}\right)$ and the standard deviation $\left(\sigma_{R}\right)$ are defined as

$\mu_{R}=f_{c}-r_{60}$

$\sigma_{R}=\sqrt{f_{s}^{2}+\mathrm{SD}\left(r_{60}\right)^{2}}$

The standard deviation of the saturation rate, $\operatorname{SD}(r)$, is shown in Figure $1 . \mathrm{SD}\left(Q_{5 \min }\right) / C_{\mathrm{VSS}}$ is the standard deviation of the 5 -min saturation rate, $r_{5}$, which is equal to the standard deviation of the 5-min flow over capacity $C_{\mathrm{vss}}$.

Parameters $f_{c}$ and $f_{s}$ depend on the share of heavy goods vehicles and are given in Table 2.

\section{Velocity Without Breakdown}

Velocity without breakdown, or mean velocity $\left(v_{m}\right)$, is not equal to project velocity $\left(v_{0}\right)$ but depends on the load and therefore on the saturation rate $\left(r_{60}\right)$. The project velocity $\left(v_{0}\right)$ is used in the Swiss design guidelines to determine the geometric properties of the new road. Velocity without breakdown $\left(v_{m}\right)$ is calculated with the following formula:

$v_{m}=\frac{v_{\text {freeflow }}}{1+\alpha \cdot r_{60}^{\beta}}$

The parameters for Equation 4 are given in Table 3.

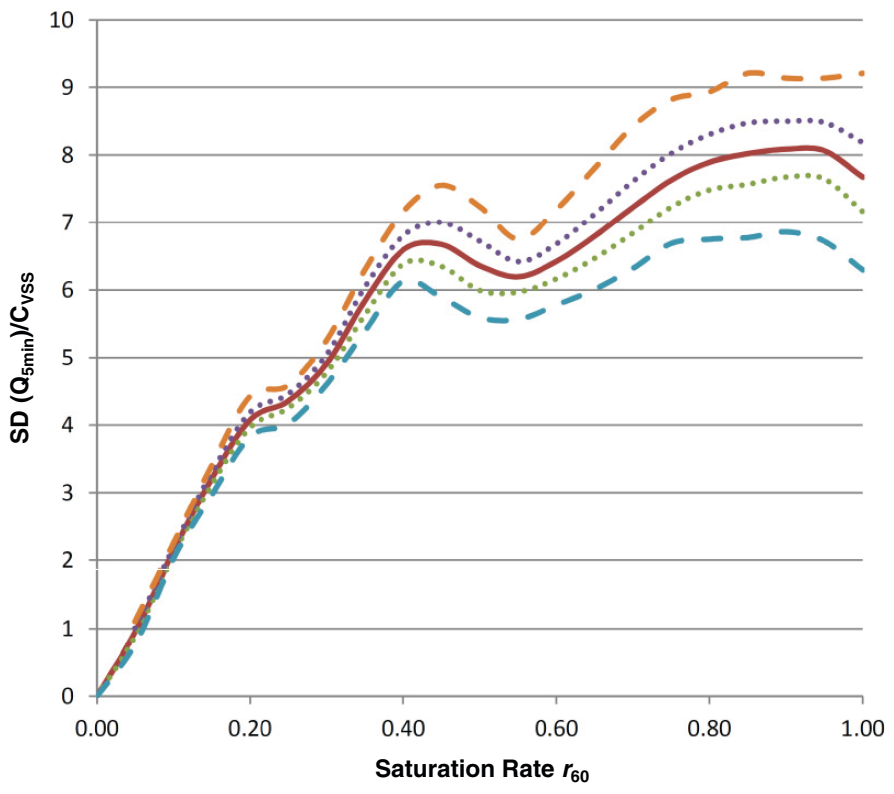

FIGURE 1 Standard deviation of saturation rate dependent on $r_{60}$.

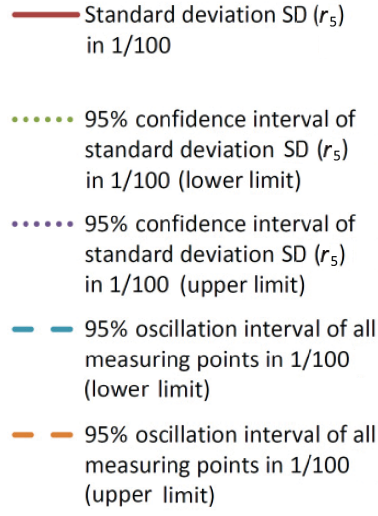


TABLE 2 Parameters for Equations 2 and 3

\begin{tabular}{lll}
\hline $\begin{array}{l}\text { Share of Heavy } \\
\text { Goods Vehicles } \\
(\%)\end{array}$ & $f_{c}$ & $f_{s}$ \\
\hline $0-5$ & 1.3305 & 0.1991 \\
$5-15$ & 1.2885 & 0.1805 \\
$15-25$ & 1.2004 & 0.1658 \\
\hline
\end{tabular}

TABLE 3 Parameters for Equation 4

\begin{tabular}{|c|c|c|c|c|c|c|}
\hline \multirow[b]{2}{*}{ Variable } & \multicolumn{2}{|c|}{$v_{0}=80 \mathrm{~km} / \mathrm{h}$} & \multicolumn{2}{|c|}{$v_{0}=100 \mathrm{~km} / \mathrm{h}$} & \multicolumn{2}{|c|}{$v_{0}=120 \mathrm{~km} / \mathrm{h}$} \\
\hline & PT & $\mathrm{HGV}$ & PT & $\mathrm{HGV}$ & $\mathrm{PT}$ & $\mathrm{HGV}$ \\
\hline$\alpha$ & 0.546 & 0.353 & 0.37 & 0.236 & 0.194 & 0.119 \\
\hline$\beta$ & 5.968 & 7.432 & 4.656 & 4.566 & 3.344 & 1.7 \\
\hline$v_{\text {freeflow }}$ & 73.6 & 72.8 & 94.4 & 84.6 & 115.2 & 96.4 \\
\hline
\end{tabular}

NOTE: $\mathrm{PT}=$ private transportation; $\mathrm{HGV}=$ heavy goods vehicle.

\section{Velocity During Breakdown}

After a breakdown, the velocity decreases abruptly for a certain period until the flow has recovered. This decrease is given by the factor $f_{m b}$, which is also volume dependent. Breakdown velocity $\left(v_{b}\right)$ is calculated as follows:

$v_{b}=f_{\mathrm{mb}} \cdot v_{m}$

Factor $f_{\mathrm{mb}}$ is calculated as

$f_{\mathrm{mb}}=c+\delta \cdot r_{60}+\frac{\gamma}{1+e^{\alpha-\beta \cdot r_{60}}}$

The parameters for Equation 5 are given in Table 4.

\section{Duration of Breakdown}

Breakdown duration $\left(t_{b}\right)$ is calculated as follows:

$t_{b}=c+\frac{\gamma}{1+e^{\alpha-\beta r_{60}}}$

The parameters for Equation 6 are given in Table 5 .

TABLE 4 Parameters for Equation 5

\begin{tabular}{lccccr}
\hline & \multicolumn{2}{l}{$v_{0}=80 / 100 \mathrm{~km} / \mathrm{h}$} & & \multicolumn{2}{c}{$v_{0}=120 \mathrm{~km} / \mathrm{h}$} \\
\cline { 2 - 3 } \cline { 6 - 6 } Variable & PT & HGV & & PT & \multicolumn{1}{c}{ HGV } \\
\hline$\alpha$ & -31.38 & -4.128 & & 3.638 & 3.055 \\
$\beta$ & -83.61 & -18.79 & & 9.223 & 7.901 \\
$\gamma$ & 0.457 & 0.388 & & -0.511 & -0.596 \\
$\delta$ & 0.432 & 0.321 & & 0.415 & 0.425 \\
$c$ & 0.126 & 0.285 & & 0.63 & 0.762 \\
\hline
\end{tabular}

TABLE 5 Parameters for Equation 6

\begin{tabular}{lcc}
\hline Variable & $v_{0}=80 / 100 \mathrm{~km} / \mathrm{h}$ & $v_{0}=120 \mathrm{~km} / \mathrm{h}$ \\
\hline$\alpha$ & 17.95 & 12.39 \\
$\beta$ & 45.37 & 34.16 \\
$\gamma$ & 0.901 & 0.34 \\
$c$ & 0.165 & 0.369 \\
\hline
\end{tabular}

\section{EXPECTED VELOCITY}

Expected velocity $\left(V_{\text {exp }}\right)$ is composed of the velocities with and without breakdown, weighted with their respective duration:

$V_{\text {exp }}=\frac{\Delta t+P_{b} \cdot t_{b} \cdot f_{\mathrm{mb}}}{\Delta t+P_{b} \cdot t_{b}} \cdot v_{m}$

where $\Delta t$ is defined as the time period for which the breakdown probability is estimated. For all calculations used in this paper, $t=1$, meaning every calculation was made for a time interval of $1 \mathrm{~h}$.

\section{Planned Velocity}

Planned velocity $\left(v_{p}\right)$ of the travelers accounts for their willingness to pay; $v_{p}$ is the velocity assumed by travelers in their scheduling.

$V_{p}=\frac{k_{\text {early }}+k_{\text {late }} \cdot P_{b} \cdot t_{b} \cdot f_{\mathrm{mb}}}{k_{\text {early }}+k_{\text {late }} \cdot P_{b} \cdot t_{b}} \cdot v_{m}$

where $k_{\text {early }}$ and $k_{\text {late }}$, the values of travel time savings (VTTS) for early and late delays in CHF (Swiss franc) per person hour (0.93 CHF = $\$ 1.00$ in September 2014), are based on the official Swiss guidelines for a cost-benefit analysis for road projects (SN 641 820).

\section{Generalized Costs in Monetary Units}

The generalized costs per person per hour per kilometer of highway $\left(K_{p, h, \mathrm{~km}}\right)$ are calculated with the expected velocity $\left(V_{\exp }\right)$, adding the share from early delay (difference between planned and mean velocity) and a share from late delay (difference between breakdown and planned velocity):

$$
\begin{aligned}
K_{p, h, \mathrm{~km}}= & \frac{k_{E} \cdot 1}{V_{\mathrm{exp}}}+\frac{\Delta t}{\Delta t+P_{b} t_{b}} \cdot k_{\mathrm{early}} \cdot\left(\frac{1}{v_{p}}-\frac{1}{v_{m}}\right) \\
& +\frac{P_{b} t_{b}}{\Delta t+P_{b} t_{b}} \cdot k_{\mathrm{late}} \cdot\left(\frac{1}{f_{\mathrm{mb}} v_{m}}-\frac{1}{v_{p}}\right)
\end{aligned}
$$

where $\Delta t$ is the length of the interval used for the estimation of the breakdown probability, and VTTS $k_{\text {early }}, k_{\text {late }}$, and $k_{E}$ are defined in Table 6. $K_{p, h, \mathrm{~km}}$ is calculated for every single hour of the year, multiplied by the respective load and summed over all $8,760 \mathrm{~h}$ of the year. For private transport this translates to

$K_{\mathrm{mIV}, \mathrm{tot}, \mathrm{km}}=\sum_{h=1}^{8,760} Q_{60, h}\left(1-\mathrm{SV}_{h}\right) \cdot r_{0} \cdot k_{p, h, \mathrm{~km}}$ 
TABLE 6 VTTS and Weights for Equations 8 and 9

\begin{tabular}{lcccc}
\hline Variable & $\begin{array}{l}\text { VTTS PT (CHF/ } \\
\text { person hour) }\end{array}$ & $\begin{array}{l}\text { Weight } \\
\text { PT }\end{array}$ & $\begin{array}{l}\text { VTTS HT (CHF/ } \\
\text { vehicle hour) }\end{array}$ & $\begin{array}{l}\text { Weight } \\
\text { HT }\end{array}$ \\
\hline$k_{E}$ & 19.74 & 2 & 53.72 & 2.25 \\
$k_{\text {early }}$ & 9.87 & 1 & 23.86 & 1.00 \\
$k_{\text {late }}$ & 29.61 & 3 & 80.58 & 3.38 \\
\hline
\end{tabular}

NOTE: $\mathrm{CHF} /$ person hour = value of one person traveling $1 \mathrm{~h} ; \mathrm{CHF} /$ vehicle hour = value of one vehicle traveling $1 \mathrm{~h} ; \mathrm{HT}=$ heavy (freight) transportation.

where $r_{0}$ is the vehicle occupancy ratio (number of people per vehicle), $\mathrm{SV}_{h}$ is the share of heavy goods vehicles, and $\mathrm{mIV}$ is motorized private transport.

For heavy goods vehicles it translates to

$K_{\mathrm{SV}, \mathrm{tot}, \mathrm{km}}=\sum_{h=1}^{8,760} Q_{60, h} \cdot \mathrm{SV}_{h} \cdot K_{\mathrm{SV}, h, \mathrm{~km}}$

where $K_{\mathrm{SV}, h, \mathrm{~km}}$ is the generalized costs for heavy goods vehicles. $K_{\mathrm{Sv}, h, \mathrm{~km}}$ is calculated in the same way as $K_{p, h, \mathrm{~km}}$ using the willingness to pay for heavy goods vehicles.

\section{Generalized Costs in Time Units}

To get the generalized costs as travel time, VTTS $k_{\text {early }}, k_{\text {late }}$, and $k_{E}$ are replaced with the respective weights in Equation 9. VTTS and weights are shown in Table 6.

\section{WYA-QM APPROACH}

The whole-year analysis model developed by Zurlinden (10) and Brilon et al. (6) is based on a bottleneck system with stochastic capacity. Each segment of a freeway is modeled as a queuing system with stochastic demand and capacity. The traffic demand and capacity volumes are estimated in 5-min intervals. To account for the stochastic variability of traffic flow processes as well as external influences such as weather conditions or incidents, the estimation of demand and capacity considers both systematic and stochastic components. On the basis of a deterministic queuing model, the total or average travel time losses caused by congestion, as well as other performance measures representing the quality of service on freeways, are determined.

\section{Traffic Demand}

The traffic demand profile is estimated in a two-step process. First, an hourly annual demand profile representing the periodic fluctuations of traffic demand during the year is estimated. Based on this, a demand profile in 5-min intervals is generated with the trend value $V$. The trend value is modeled by a piecewise linear function with 30 -min segments. On the full hour, the function value is the average of the demand volumes of the two adjacent hours. On the half hour, the function value is calculated so that the area below the piecewise linear function equals the respective hourly demand volume. The short-term stochastic variability of traffic demand is considered by applying a normal-distributed factor $F_{\text {norm }}$ with mean 1 and standard deviation of $4 / \sqrt{\mathrm{TV}}$. Traffic demand for every 5 -min interval is then given as follows:

$Q_{5 \min }=\mathrm{TV} * \frac{F_{\text {norm }}}{12}$

\section{Capacity}

The stochastic demand is compared with a stochastic capacity. For German freeways, the capacity is Weibull distributed as defined by the function $F_{\text {cap }}(6)$ :

$F_{\text {cap }}=1-e^{-\left(\frac{Q_{\text {min }}}{b}\right)^{a}}$

where

$$
\begin{aligned}
b= & 1.275 * C, \\
C= & \text { design capacity measured in 1-h intervals according to the } \\
& \text { German highway capacity manual (2), and } \\
a= & 15 .
\end{aligned}
$$

The capacity drop, which is the difference between the capacity before and the capacity after a breakdown, is accounted for by reducing the capacity by $15 \%$ in the case of congestion.

\section{Calculation of Travel Time Losses}

For calculating the travel time losses caused by traffic congestion, traffic demand and capacity are compared in each 5-min interval of the year. If the demand is greater than the capacity, vehicles queue up and congestion is generated, consisting exactly of the number of excess vehicles. The sum of travel time losses is calculated as the average number of vehicles in the queue in the interval times the interval length. The queue length at the end of each interval is calculated by the following:

$N_{i}=\max \left\{Q_{5 \min }-\underset{0}{\operatorname{cap}_{i}}+N_{i-1}\right\}$

where

$$
\begin{aligned}
N_{i} & =\text { queue length at end of interval } i, \\
Q_{5 \min } & =\text { traffic inflow in interval } i, \\
\text { cap }_{i} & =\text { capacity in interval } i, \text { and } \\
N_{i-1} & =\text { queue length in interval } i-1 .
\end{aligned}
$$

The travel time losses $T_{i}$ in each interval $i$ are determined by multiplying the average queue length with the interval length:

$T_{i}=\frac{1}{2} *\left(N_{i}+N_{i-1}\right) * t$

where $t$ is the interval length, here $5 \mathrm{~min}$.

For application, the whole year analysis model was implemented in a computer program (KAPASIM). The program estimates annual patterns of traffic demand and capacity with a random generator based on a set of input data. The comparison of traffic demand and capacity patterns is repeated several times in order to obtain average 
values of the performance indicators. Several subsequent sections of a freeway carriageway, each modeled as a queuing system, can be analyzed. The reduction of traffic volumes arriving at the downstream section $i+1$ in case of congestion in section $i$ is considered by adjusting the demand time series. The model was developed mainly to quantify overload impacts. However, delays caused by the speed-flow relationship in fluid traffic conditions can also be considered with a combined traffic flow model based on standardized speed-flow curves, which are varied in accordance with the random capacity variation (12).

\section{COMPARISON OF APPROACHES}

The approaches described in the previous sections are distinct and have different considerations and calculation methods. Table 7 gives an overview of the most important differences between the two approaches. Although in the WYA-PDM approach, the travel time in fluid traffic and the congestion externalities, early and late delay, are taken into consideration, the WYA-QM approach computes only travel time losses time losses caused by congestion. It follows that the WYA-PDM approach will calculate travel time losses also under rather lower loads, while the WYA-QM approach computes zero losses for light traffic conditions.

Another important difference, as shown in Figures 2 and 3, is that the WYA-QM approach models a freeway as a series of bottlenecks, but the WYA-PDM approach models a highway section with a specific length, so the resulting travel time losses vary according to the section length. All results of the WYA-PDM approach in this paper are for a highway section of $1 \mathrm{~km}$. The two approaches also differ in the way the intervals are connected. In the WYA-PDM approach there is no connection between the intervals; every interval is computed on its own. In the WYA-QM approach, the queue generated
TABLE 7 Comparison of WYA-PDM and WYA-QM Approaches

\begin{tabular}{|c|c|c|}
\hline Consideration & $\begin{array}{l}\text { WYA-QM } \\
\text { Approach }\end{array}$ & $\begin{array}{l}\text { WYA-PDM } \\
\text { Approach }\end{array}$ \\
\hline Interval & $5 \mathrm{~min}$ & $1 \mathrm{~h}$ \\
\hline Capacity & Stochastic & Stochastic \\
\hline Computation of travel time loss & Deterministic & Probabilistic \\
\hline Geometric layout & Local bottleneck & $\begin{array}{l}\text { Relative to } \\
\text { section length }\end{array}$ \\
\hline Drive-through time & $\mathrm{No}^{a}$ & Yes \\
\hline $\begin{array}{l}\text { Decreasing velocity without } \\
\text { breakdown }\end{array}$ & $\mathrm{No}^{a}$ & Yes \\
\hline Early and late delay & No & Yes \\
\hline Congestion & Yes & Yes \\
\hline $\begin{array}{l}\text { Impact of congestion on } \\
\text { subsequent intervals }\end{array}$ & Yes & No \\
\hline $\begin{array}{l}\text { Impact of congestion outflow } \\
\text { on subsequent sections }\end{array}$ & Yes & No \\
\hline
\end{tabular}

${ }^{a}$ Can be included by a model extension.

in an interval is carried over to the following intervals until excess capacity allows congestion to dissolve.

Annual demand profiles of the Swiss code SN 640 005b and the demand profiles as used in Germany according to Pinkofsky (11) are used to compare the two approaches. The basis for all computations is average daily traffic, of which first the demand curves and then the travel time losses are calculated. Traffic volume (average daily traffic) was varied by means of a factor of between 0.2 and 3.2. In addition, Figures 2 and 3 show the share of early and late delay of the losses calculated with the WYA-PDM approach. For all calculations

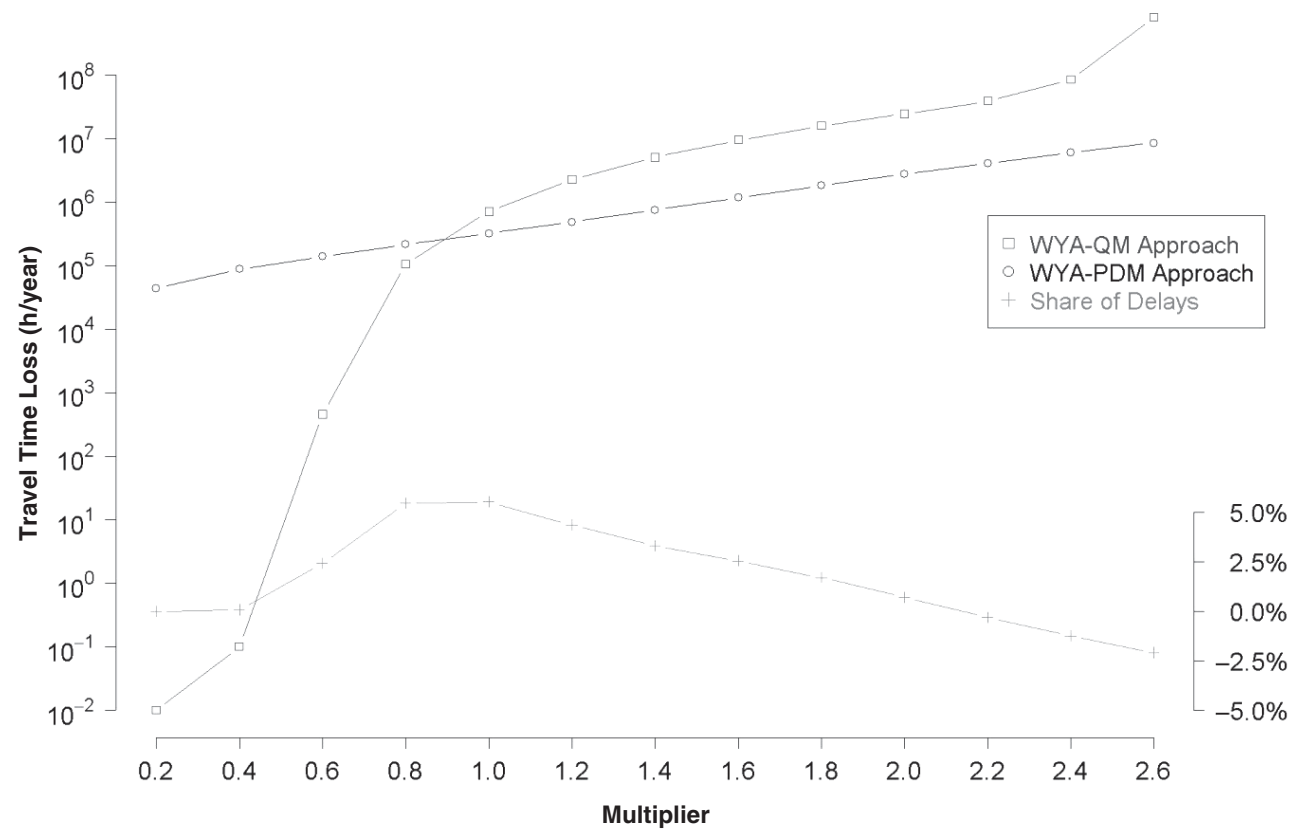

(a)

FIGURE 2 Comparison of travel time losses for Weekly Profile 2C and Demand Profile Group 2. 


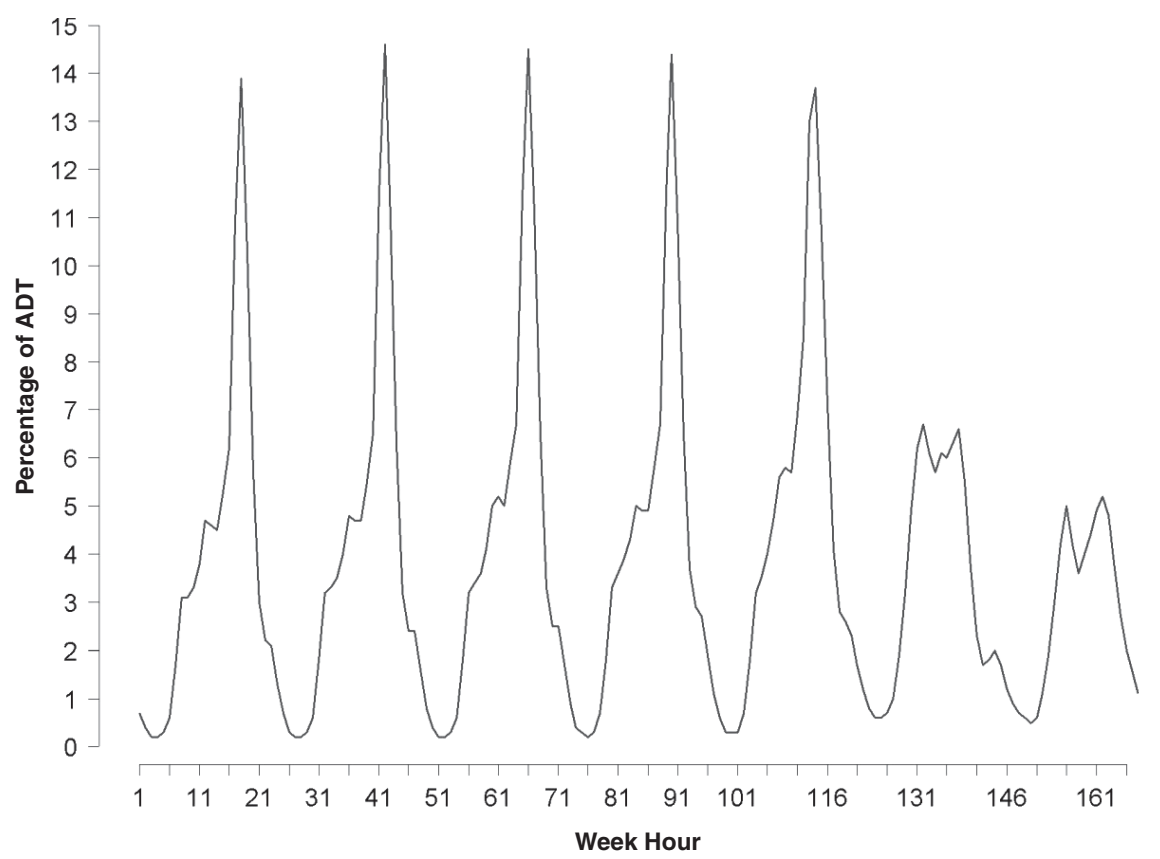

(b)

FIGURE 2 (continued) Comparison of travel time losses for Weekly Profile 2C and Demand Profile Group 2.

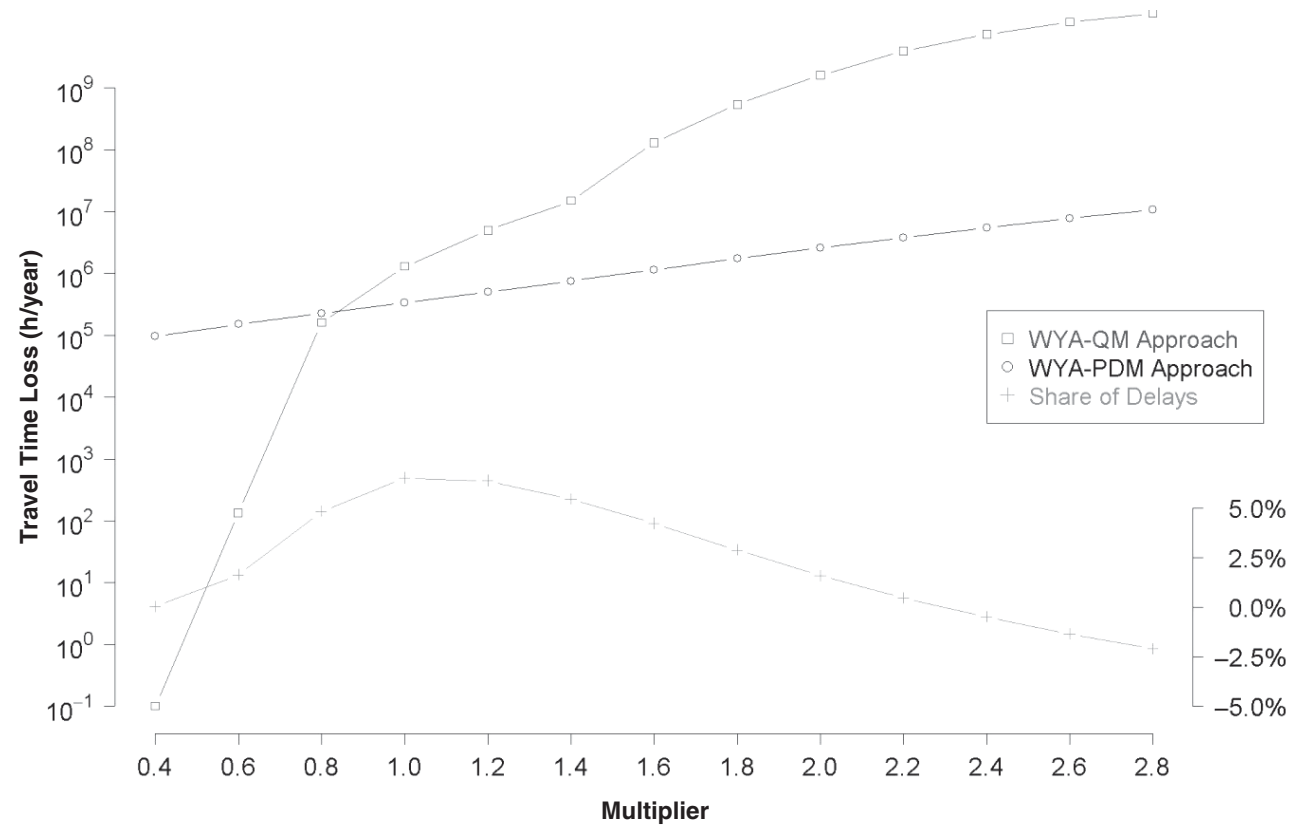

(a)

FIGURE 3 Comparison of travel time losses for Weekly Profile 7B and Demand Profile Group 7. (continued on next page) 


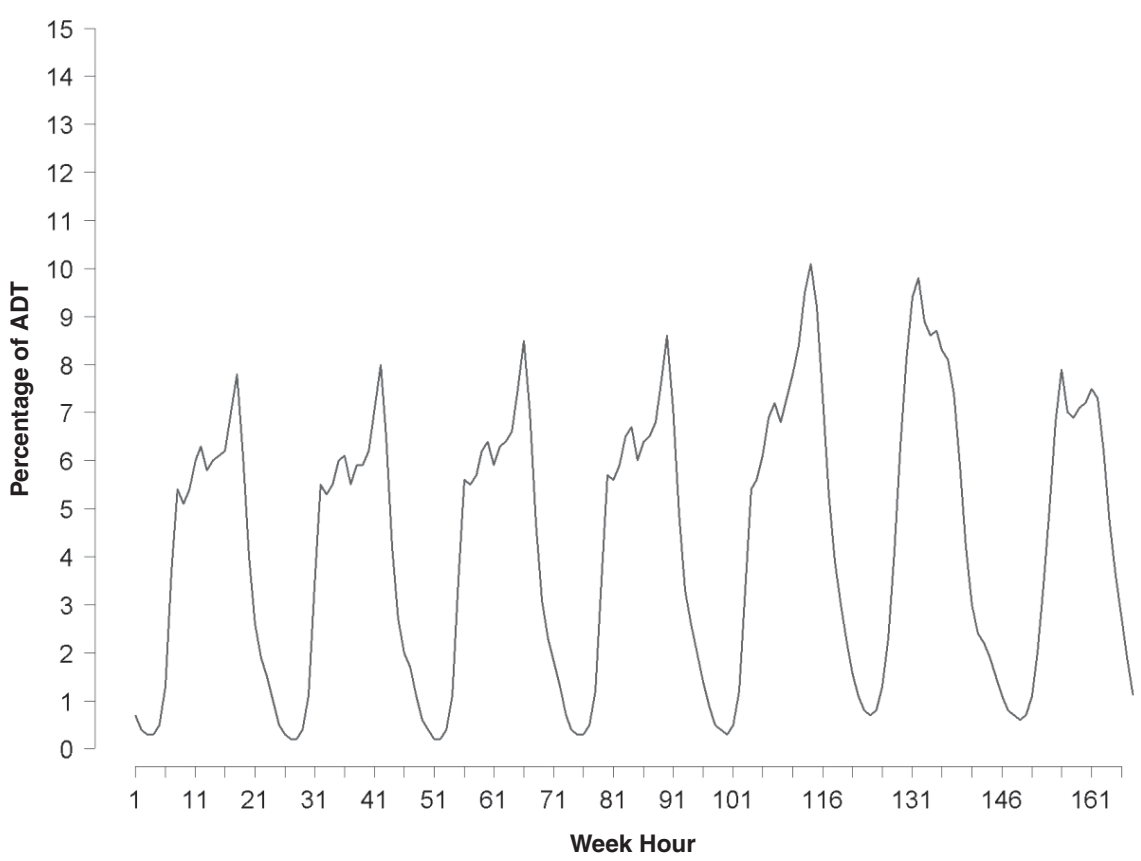

(b)

FIGURE 3 (continued) Comparison of travel time losses for Weekly Profile 7B and Demand Profile Group 7.

capacity was 4,000 vehicles per hour for a two-lane cross section. The calculations were performed with an Excel spreadsheet implemented by Jäggi et al. for the WYA-PDM approach (13) and with the program KAPASIM for the WYA-QM approach.

\section{ANNUAL DEMAND PROFILES}

The Swiss transport guideline SN 640005 b provides seven demand profiles for the week $(168 \mathrm{~h})$ and five demand profiles for the year (12 months) with which one can compose the desired load curve. In Germany, demand profiles as developed by Pinkofsky are used (11). Demand profiles for a day (24 h), a week (7 days), and a year (52 weeks) can be used to compose an hourly demand profile for a whole year, which can be used with both approaches.

\section{SWISS DEMAND PROFILES}

All combinations of weekly and annual monthly demand profiles of Swiss Code SN 640 005b were used to calculate travel time losses with both approaches. All combinations resulted in similar graphs, showing exponentially increasing travel time losses for both approaches. (The graphs are scaled logarithmically.)

The WYA-QM approach generally produces higher losses for heavy traffic conditions, although only losses caused by traffic breakdowns are considered. In the case of light traffic conditions, when no breakdowns are assumed, the simulation-based WYA-QM approach does not generate travel time losses, and the probabilistic WYA-PDM approach generates some. This results in the typical form of two exponential and crossing curves, as shown in Figures 2 and 3.

Figure 2 shows travel time losses dependent on average daily traffic for a demand profile resulting from combining hourly demand profile group 2 and annual monthly demand profile group $\mathrm{C}$ (with somewhat higher traffic in summer months). For this annual demand profile, the travel time losses of the two approaches are most similar.

Figure 3 shows travel time losses for Weekly Profile Group 7 and Annual Monthly Demand Profile Group B (with much higher traffic in summer months). This profile shows large differences in travel time losses between the approaches.

The weeklong hourly demand profiles of the respective groups given in the plots show that demand profiles with a very clear and strong daily peak (Group 2) produce more similar outcomes than demand profiles with traffic more or less equally distributed over the day (Group 7). This pattern is true for all combinations: demand profiles with one clear peak per day (Groups 1,2, and 6) produce similar outcomes, and demand profiles with a broad peak (Groups 5 and 7) or two peaks (Groups 3 and 4) produce bigger differences. The annual monthly profiles do not appear to influence differences between the approaches.

The shares of travel time losses caused by early and late delay of the WYA-PDM approach are also plotted in the figures. This share is highest around capacity limit (factor one). That makes sense because planning the arrival time is most difficult when traffic is on the edge of capacity. For low traffic or clearly overloaded conditions, one can assume that planning the trip duration is easier.

That the WYA-PDM approach, although it considers more elements, generally generates lower travel time losses for heavy traffic conditions could mean that either the breakdown probability or travel time losses during breakdown are underestimated. The WYA-PDM approach computes a breakdown probability of $100 \%$ for very high volumes, but the mean breakdown velocity never goes below $1 \mathrm{~km} / \mathrm{h}$. In addition, very long queues are never passed on to the next hour, because every hourly interval is computed independently. That means, for very high loads, that travel time losses are probably higher in reality than those computed by the WYA-PDM approach. 


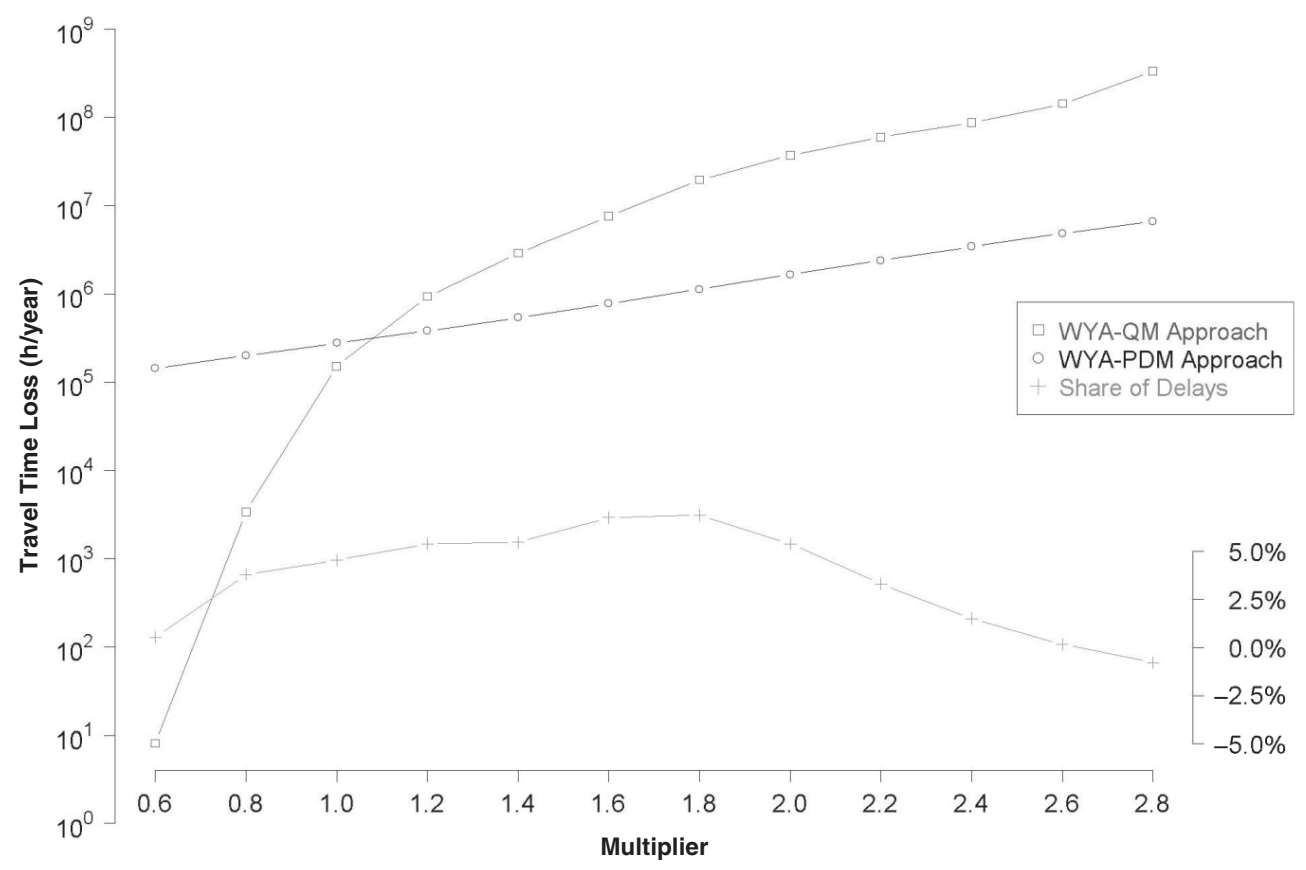

FIGURE 4 Comparison of travel time losses for Demand Profile AAA.

\section{GERMAN DEMAND PROFILES}

The German demand profiles as generated by the method of Pinkofsky (11) are composed of an hourly day-long demand profile for each Monday, average workday, Friday, Saturday, and Sunday, a daily week-long profile for variance within the week, and a weekly yearlong profile with a factor for all 52 weeks of the year. For all demand profiles there are between six and eight types, labeled $\mathrm{A}$ to $\mathrm{F}$ and $\mathrm{H}$, respectively.
Because the number of all possible combinations would be around $6^{7}>270,000$, only a selection of six demand profiles was used for comparison: AAA (day, week, and year profile of type A), BBB, CCC, DDD, EEE, and FFF. Figures 4 and 5 show the time losses for the profiles AAA and EEE.

All resulting curves are similar to those generated with the Swiss code's load curves. Both approaches produce exponentially increasing time losses, with higher losses for the WYA-QM approach. However, the differences between the demand profiles are smaller.

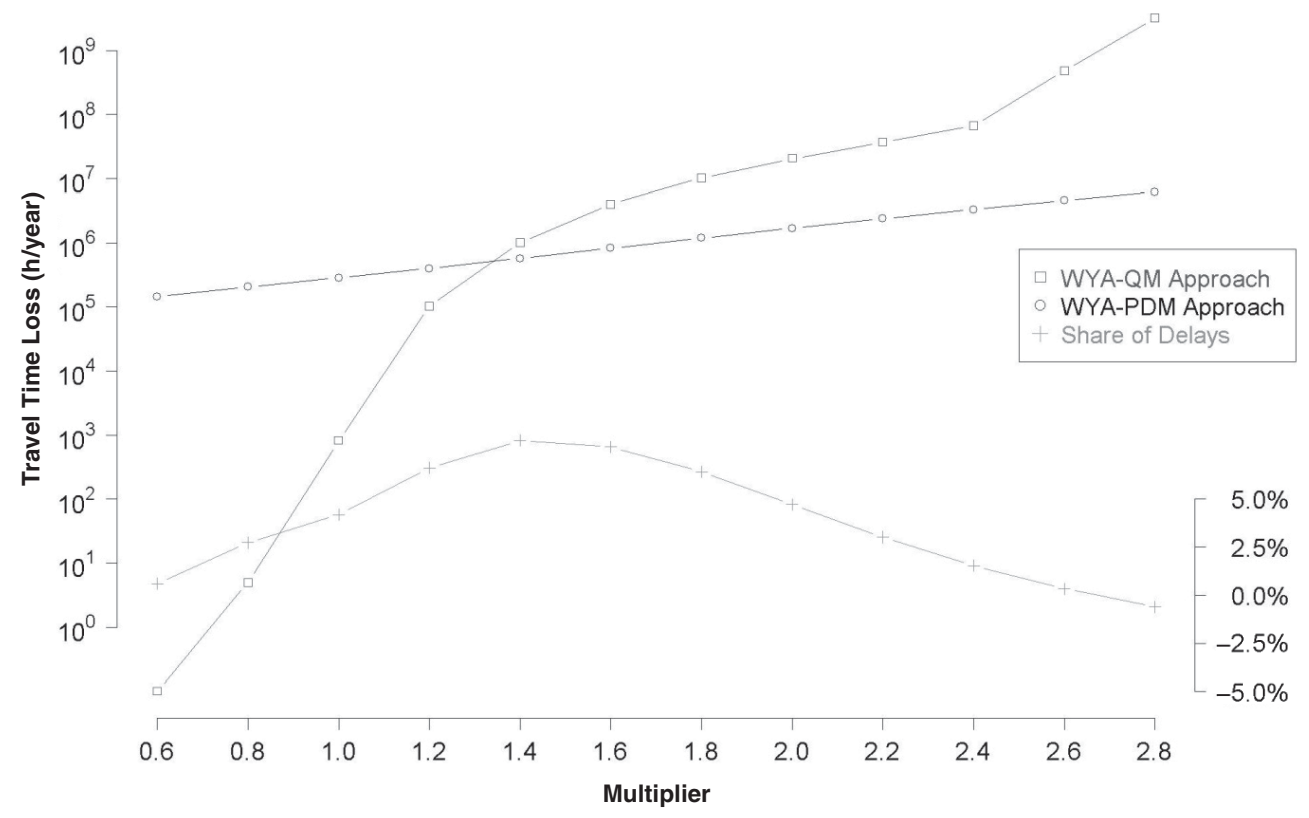

FIGURE 5 Comparison of travel time losses for Demand Profile EEE. 
TABLE 8 Share of Time Losses by Source, Load Curve 1C

\begin{tabular}{lccc}
\hline ADT & $\begin{array}{l}\text { Delayed Drive- } \\
\text { Through Time }(\%)\end{array}$ & $\begin{array}{l}\text { Early Delay } \\
(\%)\end{array}$ & \multicolumn{2}{l}{$\begin{array}{l}\text { Late Delay } \\
(\%)\end{array}$} \\
\hline 20,000 & 96.23 & 1.29 & 2.48 \\
30,000 & 93.24 & 2.43 & 4.33 \\
40,000 & 94.70 & 1.92 & 3.37 \\
100,000 & 106.79 & -4.84 & -1.94 \\
\hline
\end{tabular}

NOTE: ADT = average daily traffic.

\section{NEGATIVE GENERALIZED COSTS IN WYA-PDM APPROACH}

The share of time losses caused by early and late delay shows that the WYA-PDM approach generates negative generalized costs in the case of very high loads. The reason for this lies in the methodology itself: in the case of a breakdown probability of $100 \%$, all three velocities - planned velocity $\left(v_{p}\right)$, mean velocity $\left(v_{m}\right)$, and breakdown velocity $\left(v_{b}\right)$ - are all very low (around $3 \mathrm{~km} / \mathrm{h}$ ). $v_{p}$ falls below $v_{b}$, generating negative early delay, and $v_{m}$ falls below $v_{p}$, generating negative late delay. In other words, the conditions for early and late delay switch places and costs turn negative. A practitioner using the WYA-PDM approach can easily fix this problem by inserting a lower bound of zero for early and late delay travel time losses. In any case, this artifact occurs only with unrealistically high loads.

Table 8 shows travel time losses by source for the WYA-PDM approach for various levels of traffic; capacity is always assumed to be 4,000 vehicles per hour. Late delay always makes a higher contribution than early delay. With very high loads, early and late delay switch roles and the contribution of early delay gets bigger. Delayed driving time depicts the share of travel time losses caused by decreased expected velocity $\left(v_{\exp }\right)$ in the first term of Equation 9 , capturing the additional time a vehicle needs to drive through the section in question.

\section{CONCLUSION}

In this paper, two approaches for a whole year analysis of highway traffic flow quality were compared. A thorough examination of the approaches reveals different but typical behaviors. The differences can be explained by the respective methodologies. Travel time losses increase exponentially with increasing loads, which can be regarded as a realistic outcome. Both approaches lead to a substantial improvement in the design and decision process. They have the additional advantage of enabling the computation of informative variables like number of peak hours with mean velocity below a certain benchmark (WYA-PDM) or the total duration of congestion per year (WYA-QM).

The strength of the WYA-PDM approach lies in the evaluation of light traffic conditions and the integration of generalized early and late delay costs. The strength of the WYA-QM approach lies in the ability to more realistically estimate the time losses caused by congestion, including the impact of congestion on successive intervals and subsequent segments.

The implementation of either approach into guidelines and codes for the design of high-capacity roads can considerably improve procedures for assessment of traffic performance. It helps both the practitioner with a broader knowledge of expected traffic conditions and the decision maker with more information. Both methods are implemented in software tools and can be applied straightforwardly.

\section{REFERENCES}

1. Special Report 87: Highway Capacity Manual. HRB, National Research Council, Washington, D.C., 1965.

2. Handbuch für die Bemessung von Strassenverkehrsanlagen. Forschungsgesellschaft für Straßen- und Verkehrswesen, Cologne, Germany, 2009.

3. Bernard, M., and K.W. Axhausen. Grundlagen für eine differenzierte Bemessung von Verkehrsanlagen. Final report, SVI 2000/339. Series 1283. Swiss Federal Roads Authority, Swiss Federal Department for Environment, Transport, Energy, and Communication, Berne, Switzerland, 2008.

4. Brilon, W., H. Zurlinden, and J. Geistefeldt. Ganzjahresanalyse des Verkehrsflusses auf Autobahnen. Straßenverkehrstechnik, Vol. 11, 2004.

5. Mehran, B., and H. Nakamura. Implementing Travel Time Reliability for Evaluation of Congestion Relief Schemes on Expressways. In Transportation Research Record: Journal of the Transportation Research Board, No. 2124, Transportation Research Board of the National Academies, Washington, D.C., 2009, pp. 137-147.

6. Brilon, W., J. Geistefeldt, and H. Zurlinden. Implementing the Concept of Reliability for Highway Capacity Analysis. In Transportation Research Record: Journal of the Transportation Research Board, No. 2027, Transportation Research Board of the National Academies, Washington, D.C., 2007, pp. 1-8.

7. Minderhoud, M. M., H. Botma, and P.H.L. Bovy. Assessment of Roadway Capacity Estimation Methods. In Transportation Research Record 1572, TRB, National Research Council, Washington, D.C., 1997, pp. 59-67.

8. Lorenz, M. R., and L. Elefteriadou. Defining Freeway Capacity as Function of Breakdown Probability. In Transportation Research Record: Journal of the Transportation Research Board, No. 1776, TRB, National Research Council, Washington, D.C., 2001, pp. 43-51.

9. Bernard, M. Entwicklung eines Bemessungskonzepts für Autobahnabschnitte unter Berücksichtigung der Zufallsgrössen Verkehrsnachfrage und Kapazität in der Risikoanalyse. PhD dissertation. ETH Zurich, Switzerland, 2008.

10. Zurlinden, H. Ganzjahresanalyse des Verkehrsflusses auf Straßen. PhD dissertation. Ruhr University Bochum, Germany, 2003.

11. Pinkofsky, L. Typisierung von Ganglinien der Verkehrsstärke und ihre Eignung zur Modellierung der Verkehrsnachfrage. PhD dissertation. Technical University Braunschweig, Germany, 2006.

12. Geistefeldt, J. Estimation of Travel Times on Freeways Based on an Enhanced Traffic Flow Model. Presented at HEUREKA '05, Cologne, Germany, 2005.

13. Jäggi, B., C. Dobler, and K.W. Axhausen. Werkzeug zur aktuellen Gangliniennorm. Final report ASTRA 2010/020, Series 1412. UVEK, Berne, Switzerland, 2013.

The Highway Capacity and Quality of Service Committee peer-reviewed this paper. 